\title{
Constitutive Laws of the Reinforced Concrete Beam with the Onyx Waste Aggregate
}

\author{
Edhi Wahjuni Setyowati ${ }^{1}$, Wisnumurti ${ }^{2}$, Raharjo B.A ${ }^{3}$ \\ ${ }^{1,2}$ Departement of Civil Engineering, University of Brawijaya, Malang 65145, Indonesia \\ ${ }^{3}$ Departement of Civil Engineering, State Polytechnic of Malang, Indonesia \\ 1atitwahjuni57@gmail.com \\ ${ }^{2}$ wsmurti@ymail.com \\ 3 bobby_asukma@polinema.ac.id
}

\begin{abstract}
Onyx waste as additional aggregate in a concrete mix will enhance the compressive strength and elasticity modulus of the concrete material, eventually resulting in the change of behavior and strength of the concrete beam structure and also skew the constitutive law of reinforced concrete structure plan, especially in a reinforced concrete beam. The magnitude of stress tensile coefficient of tensile block used as a reference for reinforced concrete beam structure plan will also differ.

This study compared cylinder beam and reinforced concrete beam made from the Tulungagung onyx waste aggregate materials with cylinder beam and reinforced concrete beam made from crushed stone waste according to the established rules. The test results showed the difference in concrete strength, level of elasticity modulus and stress tensile coefficient of the tensile block. The difference of $\beta 1$ coefficient shown in the outcome of the tensile analysis of the test blocks was $1.14 \%$ for concrete made from normal aggregate and $0.3 \%$ for concrete made from onyx waste aggregate.
\end{abstract}

Keyword- constitutive law, RC beam, onyx waste

\section{INTRODUCTION}

Study of onyx waste usage has been directed for the onyx waste to be optimally used thus having economic value and support the development of Tulungagung Indonesia. One alternative way to use onyx waste is by employing it as an aggregate of the concrete mixture. Concrete made by coarse onyx aggregate inevitably differ from concrete made from the normal aggregate. The difference of aggregate type will, eventually, change the concrete strength parameters.[8],[9].[10],[11],[12],13][14]

The difference and shift of nature and strength between normal concrete and onyx concrete became the reason for routine evaluation of concrete strength planning, especially for reinforced concrete structure. Evaluation of commonly used reinforced concrete beam is important for having a better result of strength measurement analysis.

\section{LITERATURE STUDY}

\section{A. Onyx waste aggregate}

Marble Institute of America [1] described onyx as a mixture of microcrystalline, comprised of coarse calcite and aragonite. This microcrystal formed as fibril and lamellar textured-materials. Often, this stone appears as translucent materials with various projecting colors depend on the composition of various ferrous oxide. The yellowish brown color is the most common result of the ferrous oxide presence. However, sometimes we can also see the whitish, pale yellow, honey yellow, red and dark green color.

\section{B. Modulus of Elasticity of Concrete}

Nawy [2] explained that an elasticity modulus is a number describing a parameter of material strength and resistance of force-derived elastic deformation in materials. In general, elasticity modulus can be achieved through a diagram of stress and strain, defined as the curvature slope on an elastic deformation area. In concrete, the stress and strain curve is the arc appeared on the early loading phase. Therefore the elasticity modulus (modulus young) of this material is the conjunction line of the stress and strain curvature on the center point. The conjunction line slope is defined as the early tangential modulus, which can also be used for every other point within stress and strain curve. The slope of a straight line that connecting one central point to some level of stress (about $0.4 \mathrm{fc}$ ') is called pressure elasticity modulus of concrete. 
ASTM C469 - 02 [3] explained the calculation of elasticity modulus chord (Ec) as:

$$
\mathrm{E}_{\mathrm{c}}=\frac{S_{2}-S_{1}}{\varepsilon_{2}-0,00005}(\mathrm{MPa})
$$

with :

$$
\begin{array}{ll}
\mathrm{S}_{2} & =0,4 \mathrm{fc}^{\prime} \\
\mathrm{S}_{1} & =\text { stress in association to the longitudinal strain } \\
\varepsilon_{2} & =\text { longitudinal strain of } 0,4 \mathrm{fc}
\end{array}
$$

\section{Stress and strain curvature of concrete}

Many studies have been done to develop a formula to achieve better stress and strain curve. The equation of stress and strain curve of concrete studied by Popovics [4] and Thorensfeldt et al. [5] gave us stress strength of 15 to $125 \mathrm{MPa}$. The correlation between the resulting stress (fc) and the determined strain is as below:

$$
\begin{aligned}
& \frac{f c}{f c^{\prime}}=\frac{n\left(\frac{\varepsilon c}{\varepsilon o}\right)}{n-1+\left(\frac{\varepsilon \varepsilon}{\varepsilon o}\right)^{n k}} \\
& \text { with : } \\
& \mathrm{fc}^{\prime}=\text { maximum stress on test cylinder (psi) } \\
& \text { \&o }=\text { strain level in maximum stress } \\
& \mathrm{n}=\text { curve adjustment factor } \\
& =\mathrm{Ec} /\left(\mathrm{Ec}-\mathrm{E}^{\prime} \mathrm{c}\right) \\
& \mathrm{Ec}=\text { concrete elasticity modulus } \\
& \text { E'c }=\mathrm{fc} \text { '/ } 80
\end{aligned}
$$

$\mathrm{k}=$ factor determining the elevation of the curve; for $\varepsilon \mathrm{c} /$ coless than or similar to one then $\mathrm{k}=1$;for $\mathrm{c} /$ $\varepsilon 0>1$ then $\mathrm{k}=0.67$. All in psi.

D. Equivalent block stress of concrete

Tae yi [6] explained that Koenen (1866) is the first person demonstrating the theory of ultimate flexure capacity failure. He hypothesized that the stress distribution on the plane of a reinforced concrete beam is linear and uniform. Emperger (1904), and later modified by Whitney (1942), proposed an equivalent square to simplify the calculation of stress distribution theory. The distribution value of pressure stress block that occur on reinforced concrete beam surfaces forms the parabolic curve. To calculate the volume of pressure stress block by the form of parabolic is difficult, in which the parabolic pressure stress block curve is replaced by equivalent square shaped-stress block as a way to easily estimate the pressure stress without reducing the accuracy of the calculation.

The parameter beam for equivalent stress, as explained by Tae Yi [6], is shown in Figure 1
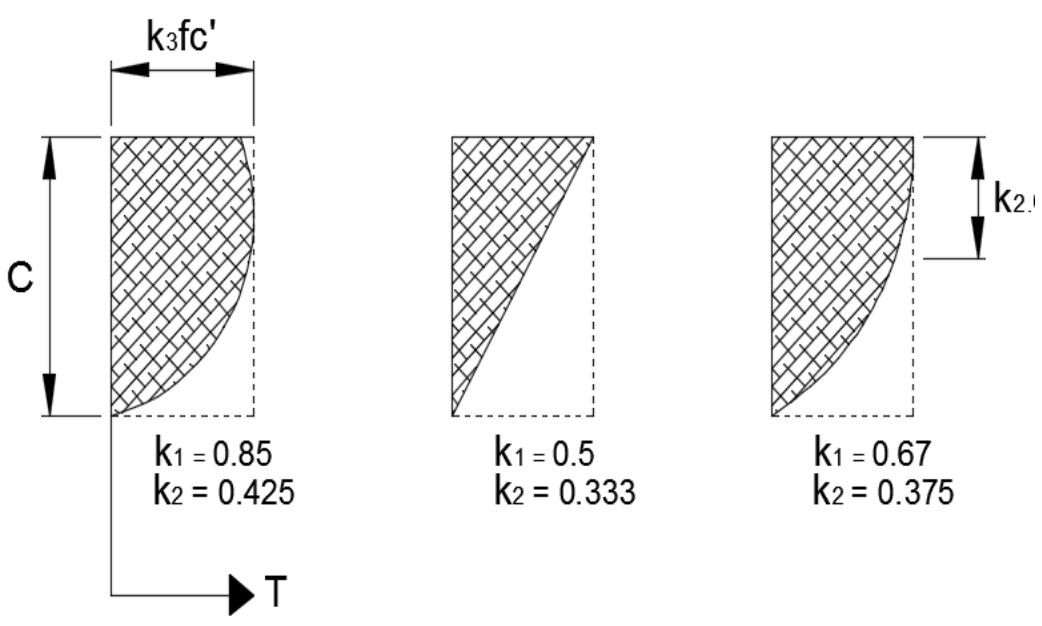

(a).Concrete

(b).Triangle

(c).Parabolic

Fig 1. Details of Stress Equivalent Block Parameter 
k3 =Maximum stress ratio of blocks and the compressive strength of cylinder block (fc')

k2 =Length ratio between maximum compressive fibril with the resultant of compressive strength toward neutral line

$\mathrm{k} 1 \quad=$ Ratio between the curvature and rectangular surface

E. Flexure strength of reinforced concrete beam

According to Wang [7], parameters used for determining the nominal strength of square surface given only steel reinforcement consists of the width of the surface (b), the effective height of the block (d) and the area of steel reinforcement (As). The value of the reinforced area (As) has resulted from a combination of all reinforced area. Concrete mantle (d') functioned as the protector of reinforcing structure toward burn and external factors. Generally, the strain strength of concrete is abandoned as it usually contributes only $10 \%$ of all pressure strength. The distribution of tensile and stretch of the reinforced concrete beam (square) can be idealized as Figure 2

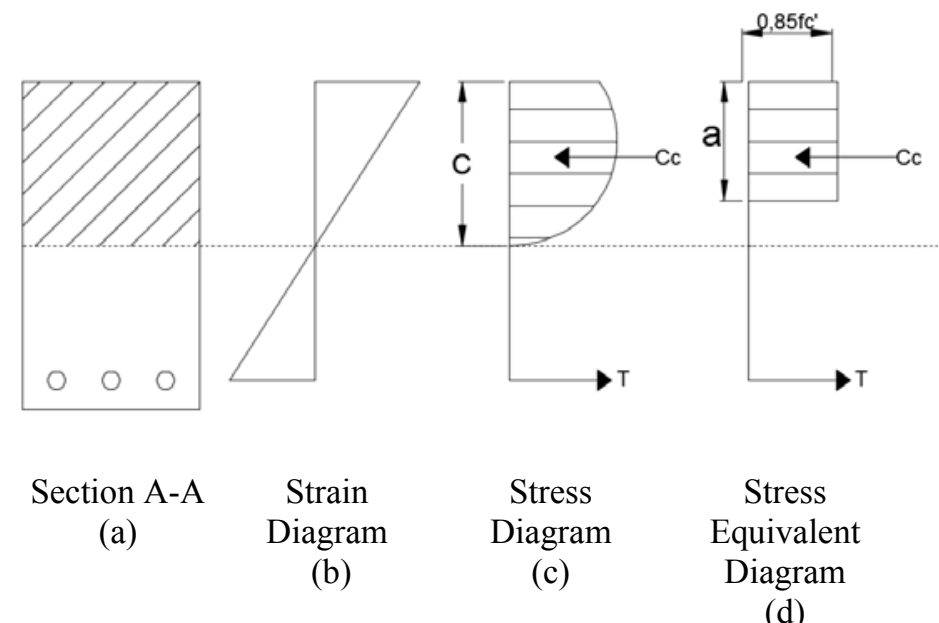

Figure 2. distribution of stress and strain on single reinforced concrete beam surface

To receive the nominal moment that can be hold by the block, the formula is as follow:

$$
\begin{array}{ll}
\mathrm{a} & =\beta 1 \times \mathrm{c} \\
\mathrm{Z} & =(\mathrm{d}-\mathrm{a} / 2) \\
\mathrm{Cc} & =\alpha \times \mathrm{f}^{\prime} \mathrm{c} \times \mathrm{b} \times \beta 1 \times \mathrm{c} \\
\mathrm{T} & =\text { As } \times \mathrm{fy}
\end{array}
$$

In balance condition:

$$
\mathrm{T}=\mathrm{Cc}
$$

The nominal moment of double reinforced concrete beam

$$
\begin{array}{ll}
\mathrm{Mn} & =\mathrm{Cc} \times \mathrm{Z} \\
\mathrm{Mn} & =\mathrm{Cc}(\mathrm{d}-\mathrm{a} / 2) \\
\text { With : } & \\
\mathrm{Cc} & =\text { Concrete compression } \\
\mathrm{As} & =\text { steel surface used for tensile reinforcement } \\
\mathrm{b} & =\text { Block width } \\
\mathrm{T} & =\text { Steel tensile strength } \\
\mathrm{a} & =\text { stress block height } \\
\beta 1 & =\text { Block Equivalent } \\
\alpha & =0,85
\end{array}
$$


A. Material investigations

\section{METHODOLOGY}

To achieve the strength parameters for the arrangement process of reinforced concrete beam strength, a material test is mandatory. The material test consists of several tests below: analysis of aggregate strainer, aggregate specific weight, the weight of aggregate contain, the water level of aggregate, aggregate absorption, steel strain strength

B. Compressive strength test and concrete elasticity modulus

Setting of pressure strength modalities given extensometer or shortening reader tools are read for later used to have the value of available strain, as if the concrete is tested for pressure strength, and the achieved results are matched with the number of specimens of pressure test as explained above, 20 specimens for each normal concrete and onyx concrete.

C. Flexure strength test of reinforced concrete beam

Total test block used, size $15 \mathrm{~cm}$ x $25 \mathrm{~cm}$ x $200 \mathrm{~cm}$, are 10 for each concrete with normal aggregate and those with onyx aggregate. Four point loading is used, and keep utilized until the reinforced concrete beam is damaged . Reinforced concrete beam with single and minimum reinforced by steel bar was tested with flexure load by giving load $\mathrm{P}$ as being described in Figure 3

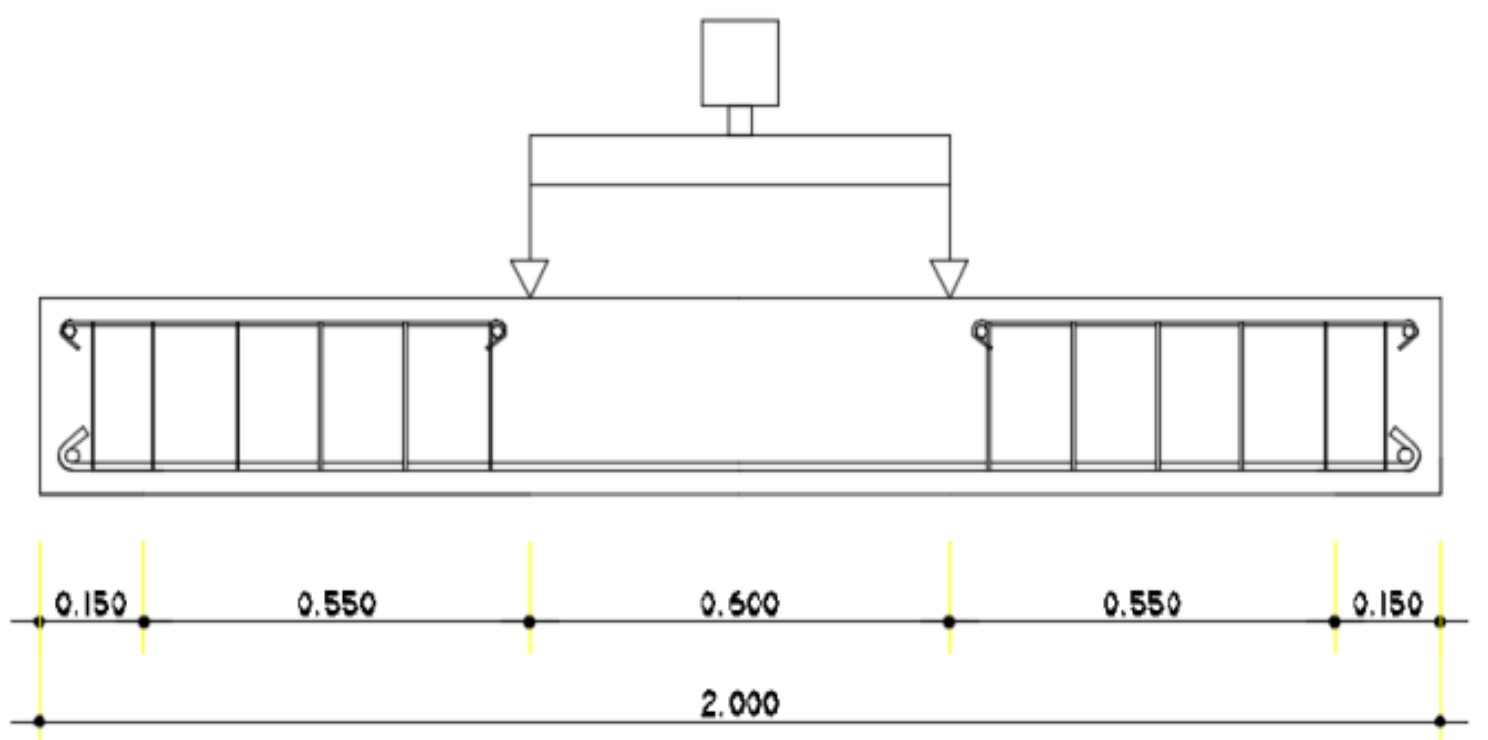

Fig 3.Reinforced Concrete beam Test Setting

\section{Data collection methods}

In this test, the data collection starts from analyzing the materials used, coarse aggregate and fine aggregate. After the test object, both the cylinder and the block, are prepared with planned quality strength of 32 $\mathrm{Mpa}$ and have been cured for 28 days. The initial data needed is the concrete stress test, which also to test the strain, and the result is the initial curve for stress-strain value in both normal concrete and onyx concrete. Next, a test for the block flexure strength is run within the loading frame. In the test, the data for flexure strength is collected according to the load given to the test objects. This research was done through following steps from materal preparation until the deliberation of discussion and conclusion. 


\section{RESULTS AND DISCUSSION}

A. Compressive strength and elasticity modulus of concrete

A total of 40 cylinder test objects are used in the concrete pressure strength test, 20 objects each for concrete with coarse pebble aggregate and concrete with coarse onyx aggregate. To get the concrete strain value, while in the process, a strain measurement tool (extensometer) is applied to the cylinder. Its function is to

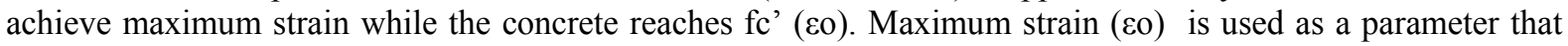
applied in the analysis of equivalent compressive strain of each test object.

Modulus elasticity of normal concrete and onyx concrete is calculated from the data of stress and strain experienced from pressure strength test, where the data is collected from every load addition of $10 \mathrm{KN}$. After the data is received, the next step is to put the data into a curve graph according to the fixed load addition. Therefore we can get a good parameter of modulus elasticity analysis as in ASTM C469. Following is the pressure strength value and modulus elasticity for each of normal concrete and onyx concrete: BN: 35722727702 and Average $\mathrm{BO}$ of $32,9227106,79 \mathrm{MPa}$.

B. Flexure strength of experimental reinforced concrete beam

To get the data of reinforced concrete block strength experimentally, a test of flexure strength is done to a total of 20 reinforced concrete blocks, where ten blocks are of concrete with coarse pebble aggregate (normal concrete) and another 10 of concrete blocks with coarse onyx aggregate. The test is run when the blocks are 28 days old and have been cured, measuring $25 \times 15 \times 200 \mathrm{~cm}$, using a single reinforced system and two loading points to get the pure flexure strength. The test is done for every $200 \mathrm{~kg}$ of load additions.

Deflection of blocks was measured using LVDT tool that was placed in the middle of block's length. The test was run until there is $20 \%$ depreciation of the former ultimate load.

In analyzing a new block compressive stress equivalent, we need a data as per formula to get the new stress-strain value. The data required are fc' (compressive strength of 28-days old concrete), $\varepsilon 0$ (the maximum strain of concrete strength), عcu(ultimate concrete strain)and Ec(concrete modulus elasticity).

Data collected from the reinforced concrete beam testing was summarized in table 1-4. The comparison result between analysis calculation and observation result of the reinforced concrete beam was concluded in table 5-6

TABLE I.Value of Block Compressive Stress Equivalent in Normal Concrete
\begin{tabular}{|c|c|c|}
\hline Name & fc' (MPa) & $\boldsymbol{\beta 1}$ \\
\hline RC-N1-1 & 30,80 & 0.912 \\
\hline RC-N1-2 & 25,77 & 0.943 \\
\hline RC-N2-2 & 30,91 & 0.912 \\
\hline RC-N3-1 & 23,11 & 0.960 \\
\hline RC-N4-1 & 31,78 & 0.906 \\
\hline RC-N5-1 & 40,16 & 0.845 \\
\hline RC-N5-2 & 43,68 & 0.817 \\
\hline RC-N6-1 & 41,78 & 0.796 \\
\hline RC-N6-2 & 30,11 & 0.916 \\
\hline RC-N7-1 & 38,77 & 0.856 \\
\hline RC-N7-2 & 37,67 & 0.856 \\
\hline RC-N8-1 & 37,56 & 0.868 \\
\hline RC-N8-2 & 39,87 & 0.847 \\
\hline RC-N9-1 & 38,71 & 0.856 \\
\hline RC-N10-1 & 41,03 & 0.840 \\
\hline RC-N10-2 & 39,87 & 0.847 \\
\hline Average & 35,72 & 0.874 \\
\hline
\end{tabular}


TABLE II.Value of Block Compressive Stress Equivalent in Onyx Concrete

\begin{tabular}{|c|c|c|}
\hline Name & fc'(MPa) $^{\prime}$ & $\boldsymbol{\beta 1}$ \\
\hline RC-O1-1 & 31,78 & 0.846 \\
\hline RC-O1-2 & 37,56 & 0.820 \\
\hline RC-O2-1 & 32,94 & 0.867 \\
\hline RC-O2-2 & 27,56 & 0.914 \\
\hline RC-O3-1 & 35,02 & 0.853 \\
\hline RC-O3-2 & 31,20 & 0.884 \\
\hline RC-O4-1 & 34,67 & 0.848 \\
\hline RC-O5-1 & 32,94 & 0.872 \\
\hline RC-O6-1 & 32,36 & 0.873 \\
\hline RC-O6-2 & 32,94 & 0.873 \\
\hline RC-O7-1 & 37,27 & 0.867 \\
\hline RC-O7-2 & 31,72 & 0.878 \\
\hline RC-O8-1 & 33,86 & 0.857 \\
\hline RC-O8-2 & 27,79 & 0.922 \\
\hline RC-O9-1 & 32,53 & 0.870 \\
\hline RC-O9-2 & 31,49 & 0.882 \\
\hline RC-O10-1 & 32,99 & 0.866 \\
\hline RC-O10-2 & 35,88 & 0.836 \\
\hline Average & 32,92 & 0.868 \\
\hline
\end{tabular}

Experimental flexure strength value that has been discussed in the previous chapters will be compared with the analytical flexure strength value, using the evaluated value of block compressive stress equivalent. The analytical calculation using the new $\beta 1$ value with block measured at $15 \times 20 \times 200 \mathrm{~cm}$ and other test object details equal to reinforced concrete block experimentally. Following is the analytical value of the flexure strength:

TABLE III.Analytical Flexure Strength of Concrete with Normal Aggregate

\begin{tabular}{|l|l|l|l|}
\hline \multirow{2}{*}{$\begin{array}{l}\text { Block } \\
\text { Code }\end{array}$} & fc' $^{\prime}$ & $\boldsymbol{\beta 1}$ & $\boldsymbol{\phi M n}$ \\
\cline { 2 - 4 } & (Mpa) & & Kg.cm \\
\hline RC-N1 & 30.80 & 0.912 & 171190,89 \\
\hline RC-N2 & 30.91 & 0.943 & 171215,68 \\
\hline RC-N3 & 23.11 & 0.912 & 168966,07 \\
\hline RC-N4 & 31.78 & 0.960 & 171395,40 \\
\hline RC-N5 & 40.16 & 0.906 & 172627,16 \\
\hline RC-N6 & 30.11 & 0.845 & 171038,00 \\
\hline RC-N7 & 37.67 & 0.817 & 172266,57 \\
\hline RC-N8 & 37.56 & 0.796 & 172346,65 \\
\hline RC-N9 & 38.71 & 0.916 & 172464,76 \\
\hline RC-N10 & 39.87 & 0.856 & 172590,28 \\
\hline
\end{tabular}

Average 171610,15 
TABLE IV.Analytical Flexure Strength of Concrete with Onyx Aggregate

\begin{tabular}{|l|l|l|l|}
\hline \multirow{2}{*}{$\begin{array}{l}\text { Block } \\
\text { Code }\end{array}$} & fc' $^{\prime}$ & $\boldsymbol{\beta 1}$ & $\boldsymbol{\phi M n}$ \\
\cline { 2 - 4 } & $\mathbf{\text { Mpa } )}$ & & Kg.cm \\
\hline RC-O1 & 31.78 & 0.846 & 170814,77 \\
\hline RC-O2 & 27.56 & 0.820 & 170231,50 \\
\hline RC-O3 & 31.20 & 0.867 & 171039,74 \\
\hline RC-O4 & 34.67 & 0.914 & 171561,70 \\
\hline RC-O5 & 32.94 & 0.853 & 171376,22 \\
\hline RC-O6 & 32.36 & 0.884 & 171239,70 \\
\hline RC-O7 & 31.72 & 0.848 & 171119,95 \\
\hline RC-O8 & 27.79 & 0.872 & 170381,56 \\
\hline RC-O9 & 31.49 & 0.873 & 171096,52 \\
\hline RC-O10 & 32.99 & 0.873 & 171331,80 \\
\hline
\end{tabular}

Average $\quad 171019,35$

C. Comparison of analytic versus experimental compressive strength

After we get the flexure strength value experimentally from the test result of each reinforced concrete block using the normal coarse aggregate and onyx waste, we tried to compare it to the flexure strength value of reinforced concrete block analytically using the $\beta 1$ value that has been modified following the value modification according to the new stress-strain diagram area. The result as follows :

Table V Analytical and Experimental Flexure Strength of Normal Concrete

\begin{tabular}{|c|c|c|}
\hline \multirow[t]{2}{*}{ Block Code } & Analytical Flexure Strength ( $\beta 1)$ & Experimental Flexure Strength \\
\hline & Kg.cm & Kg.cm \\
\hline RC-N1 & 171190,89 & 170500,00 \\
\hline RC-N2 & 171215,68 & 165000,00 \\
\hline RC-N3 & 168966,07 & 170500,00 \\
\hline RC-N4 & 171395,40 & 170500,00 \\
\hline RC-N5 & 172627,16 & 176000,00 \\
\hline RC-N6 & 171038,00 & 181500,00 \\
\hline RC-N7 & 172266,57 & 165000,00 \\
\hline RC-N8 & 172346,65 & 170500,00 \\
\hline RC-N9 & 172464,76 & 175560,00 \\
\hline RC-N10 & 172590,28 & 181197,50 \\
\hline Average & 171610,15 & 172625,75 \\
\hline
\end{tabular}

\section{CONCLUSIONS}

The conclusion of an experiment regarding the evaluation of block compressive stress equivalent $(\beta 1)$ in the reinforced concrete beam with onyx waste as follows:

1. Average pressure strength of concrete with normal aggregate is greater (35,72 Mpa), while the average pressure strength of concrete with onyx waste aggregate is 32,92 Mpa. Meanwhile, the average value of modulus elasticity of concrete with normal aggregate is $27277,02 \mathrm{Mpa}$, and the average value of those in concrete with onyx waste aggregate is 27106,79 .

2. Average value of experimental flexure strength in normal reinforced concrete with single reinforcement is $172625,75 \mathrm{~kg} . \mathrm{cm}$. It is higher than the flexure strength value of reinforced concrete block with onyx waste aggregate that is $168300 \mathrm{~kg} . \mathrm{cm}$. This is due to some factors, such as bigger value of compressive strength and modulus elasticity in the normal concrete.

3. The value of block compressive strength equivalent $(\beta 1)$ with normal aggregate is higher, measured at 0,874 , while the value of $\beta 1$ in concrete with onyx waste aggregate is 0,868 . This proves that the higher compressive strength in concrete is not necessarily resulting in lesser $\beta 1$ value, but also influenced by the value of modulus elasticity and a maximum strain of both concrete types. 
4. Average flexure strength of the analytic reinforced concrete beam is $172610,15 \mathrm{~kg} . \mathrm{cm}$., while that of experimental one is $172625,75 \mathrm{~kg} . \mathrm{cm}$. In the reinforced concrete beam with onyx waste, the value of analytical flexure strength is $171019,35 \mathrm{~kg} . \mathrm{cm}$, while those experimentally is valued at 168300,00 $\mathrm{kg} . \mathrm{cm}$. This shows if we make the flexure strength analysis using $\beta 1$ value and paying attention to the compressive strength value, modulus elasticity, and the original maximum strain, we will be able to achieve a better analytical result.

\section{REFERENCES}

[1] Marble Institute of America, Marble and Onyx, An except from the dimension stone design manual version VIII, Ohio, 2016.

[2] Nawy, Edward G,Beton Bertulang Suatu Pendekatan Dasar, Bandung, 1998.

[3] ASTM C469-94,Test Method for Static Modulus of Elasticity and Poisson's Ratio of Concrete in Compression, USA,2002.

[4] Popovics, S., A Numerical Approach to the Complete Stress-Strain Curve for Concrete,Cement andConcrete Research, V. 3, No. 5, 1973, pp. 583-599.

[5] Thorensfeldt, E., Tomaszewicz, A., and Jensen, J. J., Mechanical Properties of High-Strength Concrete and Application in Design, Proceedings of the Symposium Utilization ofHigh Strength Concrete, Tapir, Trondheim, 1987, pp. 149-159.

[6] Tae yi, S. 2002. Effect of Specimen Sizes on ACI Rectangular Stress Block for Concrete Flexural Members. ACI Structural Journal No. 99-s72.

[7] Wang, Chu-kia dan Salmon, Charles G,Reinforced Concrete Design. University of Wiconsin - Madison,1993.

[8] EdhiWahjuniSetyowati,ell, , Concrete with Onix Waste Aagregate as AestheticallyValued Structural Concrete , Green Construction and Engineering Education for Sustainable Future proceedings of the Green Construction and Engineering Education Conference,2017,AIP Conference Proceeding ,vol.1887,020013-1 - 020013-7, 2017

[9] Abdullah,G, Agoes .S, EdhiWahjuni S,Effect of Onyx Waste Aggregate as aReplacement for Rough Aggregate in the Concrete Mix Against the Elasticity Modulus of Concrete,www.sipil.studentjournal ub.ac.id ( Indonesia),2016

[10] AuliaNurul ,EdhiWahjuni S, Agoes S, Effect of Onyx Waste Aggregate as a Replacement for Rough Aggregate in the Concrete Mix Against the Stress of Concrete.,www.sipil.studentjournal.ub.ac.id (Indonesia),2016

[11] BetaTaufik R, EdhiWahjuniS,RetnoAnggraeni,. Effect of Onyx Waste Aggregate as a Replacement for Rough Aggregate in the Concrete Mix Against the Flexure Strength of Concrete, www.sipil.studentjournal.ub.ac.id ( Indonesia),2016

[12] DhitaRizkiRahmawati.EdhiWahjuni S,Effect of Onyx Waste Aggregate as a Replacement for Rough Aggregate in the Concrete Mix Against the Compressive Strength of Concrete. ,www.sipil.studentjournal. ub.ac.id ( Indonesia )

[13] KarisaRatih Natalia, EdhiWahyuniSetyowati, EkoAndiSuryo ,The MicroStructure of Concrete Made from Onyx Waste Replacing the Rough Aggregate., www.sipil.studentjournal.ub.ac.id (Indonesia),2016

[14] EdhiWahjuniSetyowati, The Compressive Strength of Tulungagung Onyx Waste Concrete ,Jurnal Media TeknikSipil (,Indonesia ) 2016 